\title{
Dorsal Plate Osteosynthesis in Simple and Complex Fractures of the Distal Radius: A Radiological Analysis of 166 Cases
}

\author{
Haval Ghafoor ${ }^{1, *}$ Mathias Haefeli, MD ${ }^{2, *}$ Regula Steiger, MD ${ }^{1,3}$ Philipp Honigmann, MD ${ }^{1,4,5}$
}

\footnotetext{
${ }^{1}$ Hand Surgery, Kantonsspital Baselland, Liestal, Switzerland

${ }^{2}$ Hand Surgery, Kantonsspital Graubünden, Chur, Switzerland

${ }^{3}$ Orthopraxis Lusser, Allschwil, Switzerland

${ }^{4}$ Department of Biomedical Engineering and Physics, Amsterdam Movement Sciences, Amsterdam UMC, University of Amsterdam, Amsterdam, The Netherlands

${ }^{5}$ Department of Biomedical Engineering, Medical Additive Manufacturing Research Group, University of Basel, Allschwil, Switzerland
}

J Wrist Surg 2022;11:134-144.
Address for correspondence Philipp Honigmann, MD, Hand Surgery, Kantonsspital Baselland, Mühlemattstrasse 13, 4410 Liestal, Switzerland (e-mail: philipp.honigmann@ksbl.ch).

\begin{abstract}
Keywords

- distal radius fractures

- dorsal plates

- ORIF

- Pi-plate
\end{abstract}

Background To report the radiologic outcome and rate of complications of open reduction and internal fixation (ORIF) using a dorsal plate fixation of simple and complex distal radius fractures in adult patients.

Methods Patients treated with dorsal ORIF of simple and complex distal radius fractures between December 2008 and April 2013 were included in this single-center retrospective study. Type of fracture, radiographic measurements, and complications were documented. Results One-hundred and sixty-six patients/fractures were included. Restoration of radial inclination $\left(22^{\circ} \pm 3^{\circ}\right)$ was achieved in $38 \%$. Radial height $(14 \pm 1 \mathrm{~mm})$ was least likely to be restored to normal values postoperative in $25 \%$. Normal ulnar variance $(0.7 \pm 1.5 \mathrm{~mm})$ could be observed in $60 \%$ and adequate volar tilt $\left(11^{\circ} \pm 5^{\circ}\right)$ was achieved in $50 \%$ at final follow-up. We observed one loss of reduction in an AO type C2 fracture and a total of 15 nonimplant-related minor clinical complications.

Conclusion Our radiographic findings after dorsal plating are comparable to those published on volar plating. The changes in radial height and volar tilt could be attributed to projection-related differences in the radiographs and did not signify a loss of reduction in all cases.

Clinical Relevance Dorsal plating of distal radius fractures is safe and remains an important approach in the treatment of complex distal radius fractures. Complications in our study were even less compared to those reported in the literature.

Type of Study/Level of Evidence This is a Type IV study.

Level of Experience of Surgeons The level of experience of surgeons is III-V.

These authors contributed equally.

received

December 12, 2020

accepted after revision

August 3, 2021

published online

October 1, 2021
DOI https://doi.org/

$10.1055 / \mathrm{s}-0041-1735839$.

ISSN 2163-3916.

\footnotetext{
(c) 2021. The Author(s).

This is an open access article published by Thieme under the terms of the Creative Commons Attribution-NonDerivative-NonCommercial-License, permitting copying and reproduction so long as the original work is given appropriate credit. Contents may not be used for commercial purposes, or adapted, remixed, transformed or built upon. (https://creativecommons.org/ licenses/by-nc-nd/4.0/)

Thieme Medical Publishers, Inc., 333 Seventh Avenue, 18th Floor, New York, NY 10001, USA
} 
Optimal fracture treatment should aim for stable anatomical reduction to allow for early active motion of the wrist to restore functionality. ${ }^{1-3}$

Decision making of the approach is often based on the direction of the dislocated fragments and on the surgeon's preference and experience. ${ }^{4-10}$ Many fracture types of the distal radius can be treated with volar plating, also combined with arthroscopy. ${ }^{8,9}$ Despite this trend, there are still fracture patterns which need to be addressed from the dorsal aspect of the distal radius especially in cases of Barton-like fractures, fractures of the dorso-ulnar corner, and complex dorsally comminuted fracture patterns. Improved understanding of biomechanics of the wrist and the role of dislocation of biomechanical units in unstable fracture situations should guide the decision making nowadays. ${ }^{11}$

Advantages of dorsal plating include better visualization of intra-articular fracture fragments and displacement by arthrotomy and better support against dorsal collapse. ${ }^{12}$ The dorsal approach is less favored by surgeons because of the reported higher rate of complications caused by the approach and the implant itself when using older, bulky, and less anatomically shaped implants for dorsal plating. They are associated with a higher rate of complications such as extensor tendon rupture, tenosynovitis, or implant-related soft-tissue irritation. ${ }^{5,12-16}$

Modern implants, like the one used in our patient cohort, are anatomically shaped, provide a low profile, and allow for placement of angular stable screws. ${ }^{17}$ They ensure excellent stability and cause less complications. ${ }^{18}$ Wei et al showed in a meta-analysis that there is no significant between-group difference in overall complication rates between patients treated by volar plating versus patients treated by dorsal plating. Volar fixation was associated more often with neuropathy and carpal tunnel syndrome (CTS), whereas the dorsal approach is associated with more tendon irritation. ${ }^{13}$

In combination with the use of a dorsal retinacular flap, complications of the dorsal approach are nowadays equal to those of volar plating. ${ }^{17}$

The goal of this study was to compare clinical and radiographical results of patients treated with dorsal plating of distal radius fractures from 2008 until 2013 with accepted radiographic ranges in literature and outcome in patients treated by a volar approach.

\section{Materials and Methods}

One-hundred and sixty-six patients with the minimum age of 18 years treated for distal radius fractures by open reduction and internal fixation (ORIF) using a low-profile dorsal frame plate ( - Fig. 1) between December 2008 and April 2013 in our hand surgical unit were included in the study. Correctly projected anterior-posterior (PA)/lateral radiographs preand postoperatively, after 4,8 , and 12 to 16 weeks and after removal of implant were mandatory for inclusion (-Fig. 2). Patients with accompanying fractures of the ulna (other than the ulnar styloid) were excluded from the study. Radiographs with inadequate quality were excluded in consensus with all authors to ensure accurate measurements.

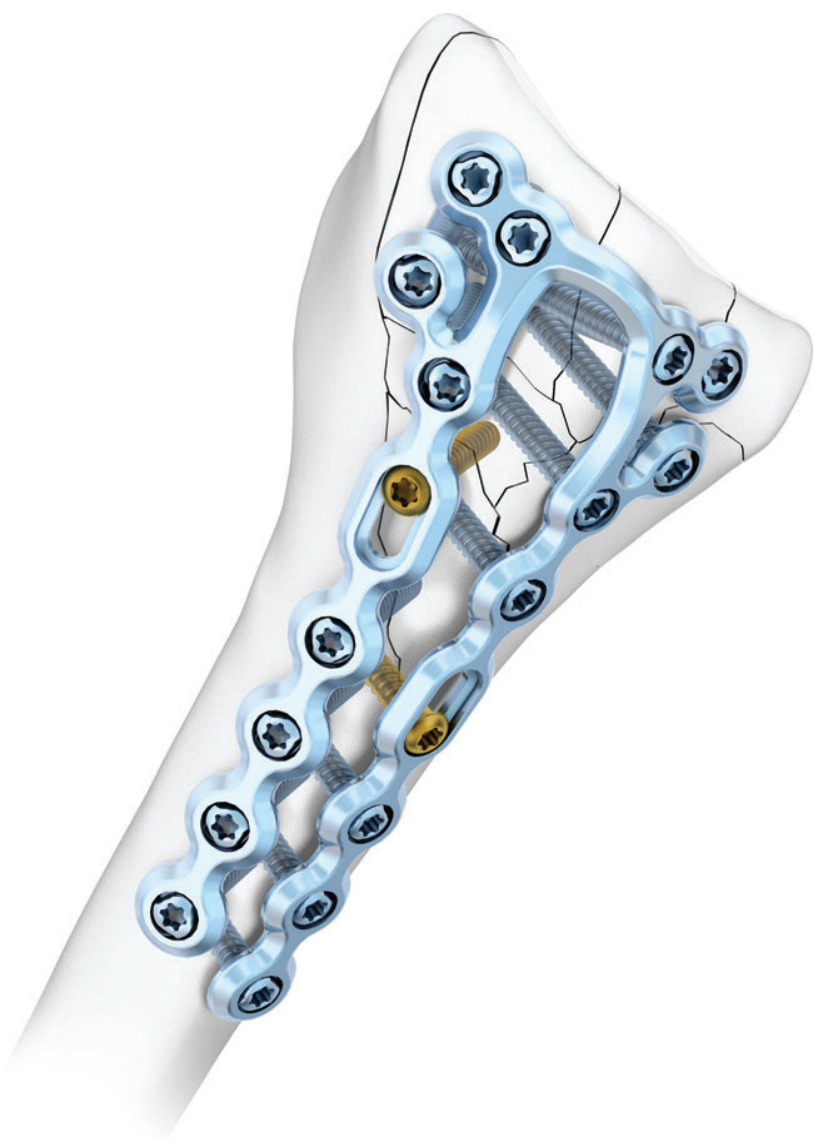

Fig. 12.5 TriLock distal radius plates, dorsal (Medartis AG, Basel, Switzerland).

Patient selection for the study is shown in - Fig. 3. Of the 576 eligible distal radius fractures, 35 were conservatively treated, 38 received a dorso-volar ORIF, 172 a volar ORIF, and 7 were treated with other methods. Of the 324 fractures which were treated with a dorsal ORIF, we had to exclude 158 because of insufficient follow-up (e.g., no radiographs in the mentioned intervals, follow-up shorter than 3 months, no removal of implant, insufficient quality of $\mathrm{X}$-rays). One hundred and sixty-six fractures were available for study.

In our study, decision making of the chosen approach was based on computed tomography. We use low-radiation and low-cost cone-beam computed tomography (CBCT) in our institution. ${ }^{19,20}$

One resident (G.H., level of experience III) retrospectively collected clinical data using Polypoint KIS (Erne Consulting AG, Gümlingen, Switzerland). Radiographs were identified in PACS IntelliSpace (Phillips Healthcare, Phillips, Amsterdam, the Netherlands) and exported to IMS Client (Imagic Bildverarbeitung AG, Glattbrugg, Switzerland) for measurement. All data were collected in Microsoft Excel (Microsoft Corporation, Redmond, WA).

The anonymized PA and lateral (lat.) radiographs from time of injury, initial postoperative follow-up, after 4 weeks, after 8 weeks, after 3 to 4 months, and after removal of implants were reviewed and measured by the resident and an expert hand surgeon (level V). 

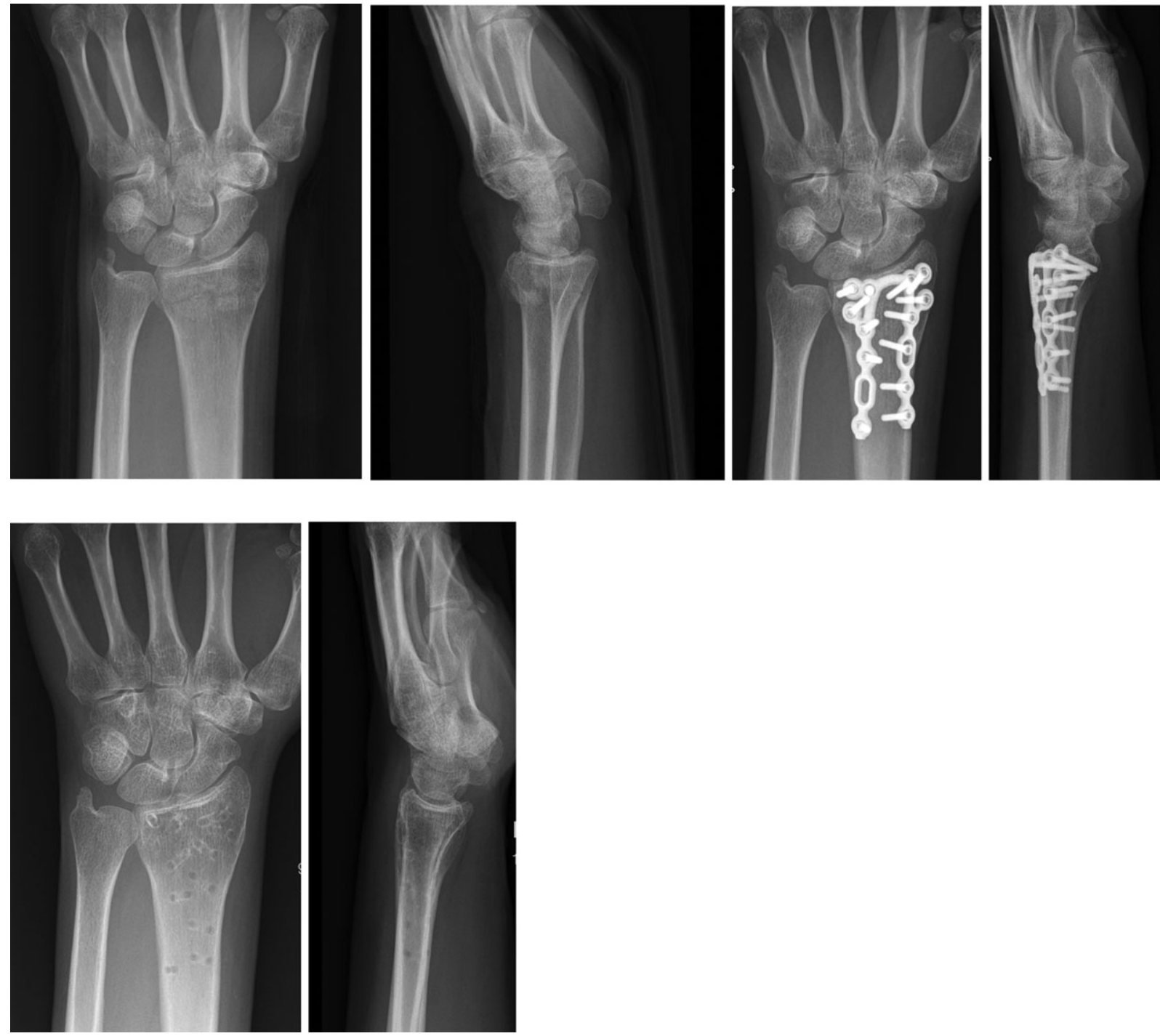

Fig. 2 X-rays AP/lat (trauma, 4 weeks postoperatively and after removal of implant). AP, anterior-posterior; lat, lateral.

Fractures were classified according to the Fernandez classification $^{21}$ and the revised AO classification ${ }^{22}$ (Revised AO/OTA classification, January 2018, AO Foundation, Davos, Switzerland). Radial inclination, radial height, ulnar variance, and volar tilt were measured. Radiographs at the time of injury and after implant removal were additionally measured for articular gap and articular step-off. Results were recorded in millimeters or degrees. Dorsal/volar translation was also measured in the injury films and divided into dorsal/volar groups 1 to 3 .

Additionally, the occurrence of fractures of the ulnar styloid was also documented and classified with the $\mathrm{AO}$ Fracture classification (AO 2U3 A1.1 and A1.2).

Methods for obtaining the measurements were according to the principal axis factoring analysis described by Herzberg $\left(-\right.$ Fig. 4). ${ }^{23}$ Normal reference values and ranges are summarized in - Table 1.

Radial inclination (-Fig. 4A) was measured on the PA radiograph by creating a line perpendicular the long axis of the radius that touches the ulnar end of the radial plateau and then taking the angle between that line and a line drawn from that ulnar edge of the radius to the tip of the radial styloid. Normal radial inclination was considered to be $22^{\circ} \pm 3^{\circ} .24,25$

Radial height ( - Fig. 4B) was measured by drawing a line through the long axis of the radius and then extending a perpendicular line to it through the ulnar corner of the lunate fossa. Another line parallel to this perpendicular line was drawn through the tip of the radial styloid. The distance between these two parallel lines was measured along the long axis of the radius. We considered normal radial height to be $14 \pm 1 \mathrm{~mm}^{26}$

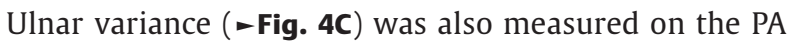
radiograph by creating two perpendicular lines to the long axis of the radius, one extending through the ulnar-most corner of the lunate fossa and one touching the most distal point of the ulnar dome and measuring the distance between those two through the long axis of the radius. Results were recorded in millimeters, whereas negative numbers meant an ulna negative and positive numbers an ulnar positive. Normal ulnar variance was defined as $0.7 \pm 1.5 \mathrm{~mm}^{27}$ 


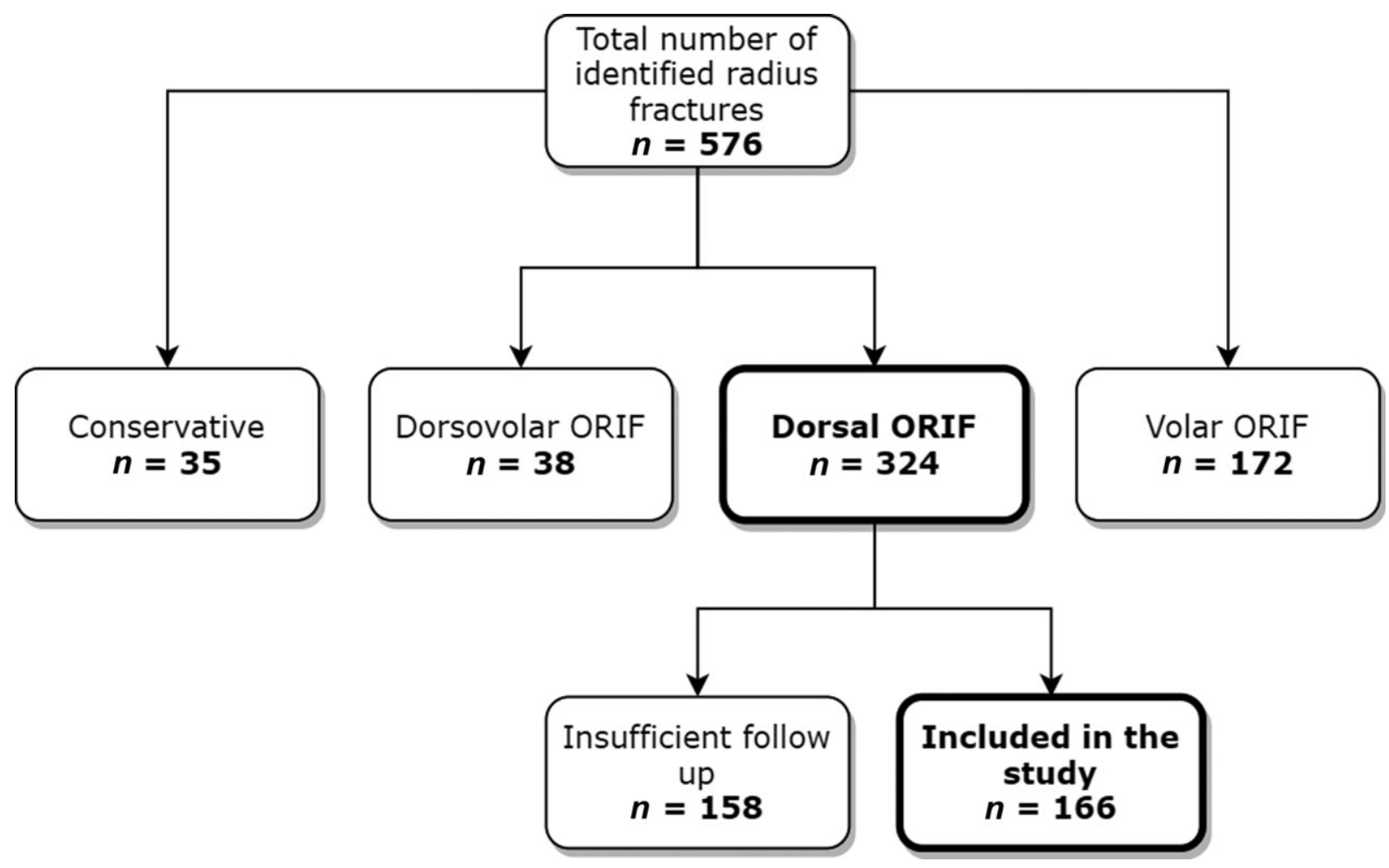

Fig. 3 Eligibility of patients and reasons for exclusion.
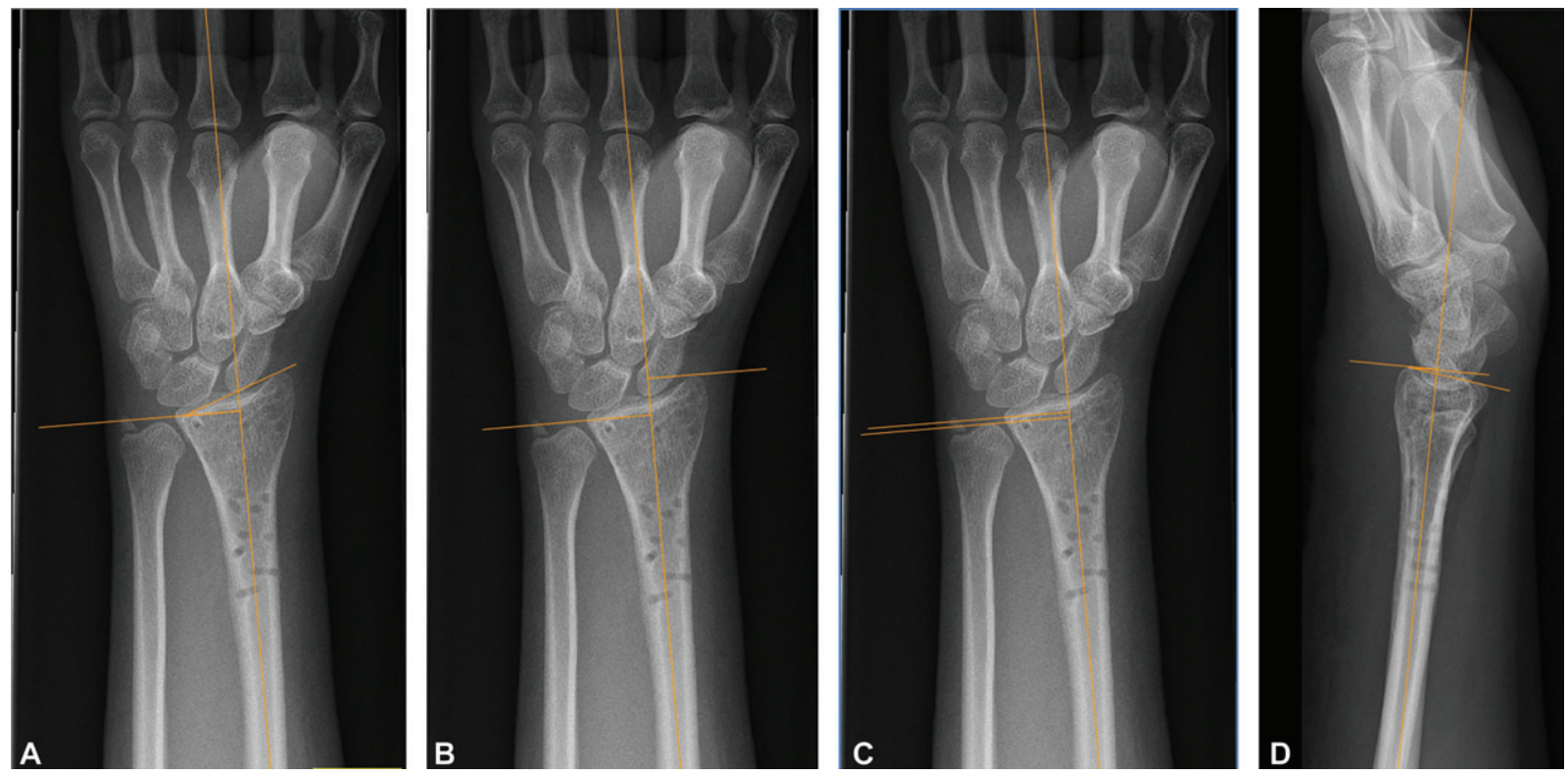

Fig. 4 Methods of measurements (from left to right) for (A) radial inclination, (B) radial height, (C) ulnar variance, and (D) volar tilt.

Volar tilt ( - Fig. 4D) was measured on the lateral film by again using the long axis of the radius as a reference and creating a perpendicular line to it that touches the most volar point of the articular surface. We then drew another line through that point and the most dorsal point of the articular surface, the angle between those two lines was then documented as volar tilt. ${ }^{28,29}$ Normal volar tilt was considered to be $11^{\circ} \pm 5^{\circ} .30$
We additionally defined functional ranges for all measurements apart from radial height according to accepted outcomes in literature: $\leq 20^{\circ}$ dorsal tilt, $\geq 10^{\circ}$ radial inclination, $\leq 5 \mathrm{~mm}$ ulnar variance, and $<2 \mathrm{~mm}$ step-off. ${ }^{28,29,31,32}$

Articular congruency was measured by examining the articular surface on the PA or lateral film. Any step-off was measured and recorded as either less than $2 \mathrm{~mm}$ or $2 \mathrm{~mm}$ and more. This cut-off was chosen based on the work of Knirk and 
Table 1 Normal reference values and ranges

\begin{tabular}{|l|l|}
\hline & Standard values \\
\hline Radial inclination & $22^{\circ} \pm 3^{\circ 24,25}$ \\
\hline Radial height & $14 \pm 1 \mathrm{~mm}^{26}$ \\
\hline Ulnar variance & $0.7 \pm 1.5 \mathrm{~mm}^{27}$ \\
\hline Volar tilt & $11^{\circ} \pm 5^{\circ 30}$ \\
\hline Step-off & $<2 \mathrm{~mm}^{32,33}$ \\
\hline Gap & $<2 \mathrm{~mm}^{32,33}$ \\
\hline
\end{tabular}

Jupiter $^{32}$ that showed the significantly higher occurrence of posttraumatic arthritis of the wrist in patients with an articular step-off greater than $2 \mathrm{~mm}$ after operative reduction and fixation and on Lalone et al. ${ }^{33}$ The same criteria were used to measure articular gap.

The study has been approved by the local ethical committee (EKNZ 2016-00303).

\section{Results}

\section{Patient and Fracture Characteristics}

The mean age of the 166 patients ( 131 female, 35 male) was 58.8 years (range $18-84$ ), as seen in - Table 2 . The left hand
Table 2 Patient demographics

\begin{tabular}{|c|c|c|c|c|}
\hline & & \multirow{2}{*}{$\begin{array}{l}\text { Mean } \\
\text { age (y) }\end{array}$} & \multirow{2}{*}{$\begin{array}{l}\text { Median } \\
\text { age }(y)\end{array}$} & $(n=166)$ \\
\hline & & & & Range (y) \\
\hline Age (y) & & 58.83 & 61 & $18-84$ \\
\hline \multirow[t]{2}{*}{ Sex } & Male & 35 & $21.08 \%$ & \\
\hline & Female & 131 & $78.92 \%$ & \\
\hline \multirow{2}{*}{$\begin{array}{l}\text { Injured } \\
\text { hand }(n)\end{array}$} & Right & 69 & $41.57 \%$ & \\
\hline & Left & 97 & $58.43 \%$ & \\
\hline \multicolumn{2}{|c|}{$\begin{array}{l}\text { Fracture of } \\
\text { the ulnar } \\
\text { styloid }(n)\end{array}$} & 70 & $42.17 \%$ & \\
\hline & A1.1 & 21 & $12.65 \%$ & \\
\hline & A1.2 & 49 & $29.52 \%$ & \\
\hline
\end{tabular}

was affected in 97 and the right in 69 cases, respectively. Seventy cases had a concomitant fracture of the ulnar styloid (49 at the base). We had 79 A, 9 B, and 78 C-type fractures, according to the revised AO classification. Fracture distribution according to the Fernandez classification showed 74 type I, 10 type II, 80 type III, 0 type IV, and 2 type $\mathrm{V}$ fractures.

Table 3 Values for the injury X-ray film

\begin{tabular}{|c|c|c|c|c|c|}
\hline & $N$ & Radial Inclination & Radial height & Ulnar variance & Volar tilt \\
\hline Overall (\% [n]) & 166 & $39.16 \%(65)$ & $3.61 \%(6)$ & $45.78 \%(76)$ & $5.42 \%(9)$ \\
\hline \multicolumn{2}{|l|}{ Mean (SD) } & $17.84^{\circ}\left(6.59^{\circ}\right)$ & $8.48 \mathrm{~mm}(3.17 \mathrm{~mm})$ & $2.17 \mathrm{~mm}(2.01 \mathrm{~mm})$ & $-18.11^{\circ}\left(14.1^{\circ}\right)$ \\
\hline \multicolumn{2}{|c|}{ Minimum to maximum } & $-0.6^{\circ}$ to $45.8^{\circ}$ & -0.2 to $19.4 \mathrm{~mm}$ & -2.5 to $8 \mathrm{~mm}$ & $-50.8^{\circ}$ to $15.6^{\circ}$ \\
\hline \multicolumn{6}{|l|}{ AO class $(\%[n])$} \\
\hline A1 & 0 & $0 \%(0)$ & $0 \%(0)$ & $0 \%(0)$ & $0 \%(0)$ \\
\hline $\mathrm{A} 2$ & 32 & $31.25 \%(10)$ & $0 \%(0)$ & $40.63 \%(13)$ & $3.13 \%(1)$ \\
\hline A3 & 47 & $36.17 \%(17)$ & $0 \%(0)$ & $51.06 \%(24)$ & $0 \%(0)$ \\
\hline B1 & 6 & $50 \%(3)$ & $0 \%(0)$ & $50 \%(3)$ & $50 \%(3)$ \\
\hline B2 & 3 & $0 \%(0)$ & $0 \%(0)$ & $33.33 \%(1)$ & $0 \%(0)$ \\
\hline B3 & 0 & $0 \%(0)$ & $0 \%(0)$ & $0 \%(0)$ & $0 \%(0)$ \\
\hline C1 & 30 & $40 \%(12)$ & $6.67 \%(2)$ & $53.33 \%(16)$ & $10 \%(3)$ \\
\hline $\mathrm{C} 2$ & 25 & $56 \%(14)$ & $4 \%(1)$ & $52 \%(13)$ & $4 \%(1)$ \\
\hline $\mathrm{C} 3$ & 23 & $39.13 \%(9)$ & $13.04 \%(3)$ & $26.09 \%(6)$ & $4.35 \%(1)$ \\
\hline \multicolumn{6}{|c|}{ Fernandez class (\% $[n])$} \\
\hline 1 & 74 & $36.49 \%(27)$ & $0 \%(0)$ & $45.95 \%(34)$ & $1.35 \%(1)$ \\
\hline 2 & 10 & $30 \%(3)$ & $20 \%(2)$ & $30 \%(3)$ & $40 \%(4)$ \\
\hline 3 & 80 & $42.5 \%(34)$ & $3.8 \%(3)$ & $47.5 \%(38)$ & $5 \%(4)$ \\
\hline 4 & 0 & $0 \%(0)$ & $0 \%(0)$ & $0 \%(0)$ & $0 \%(0)$ \\
\hline 5 & 2 & $50 \%(1)$ & $50 \%(1)$ & $50 \%(1)$ & $0 \%(0)$ \\
\hline Step-off & Gap & & & & \\
\hline $97.59 \%(162)$ & $91.57 \%(152)$ & & & & \\
\hline
\end{tabular}

Abbreviation: SD, standard deviation. 


\section{Radiographic Results}

Measurements in preoperative films were not within the range of radiographic norms due to the dislocation of the fracture (-Table $\mathbf{3}$ ).

For the first film postoperatively (range 1-3 days postoperatively), more than $50 \%$ of all patients achieved measurements within the norm for radial inclination, ulnar variance, and volar tilt. Only $14 \%$ were within norm for radial height (-Table 4).

For the first follow-up ( 4 weeks after surgery), more than $50 \%$ reached the radiographic norms for ulnar variance and volar tilt. Only $42 \%$ were within norms for radial inclination and $23 \%$ for radial height.

The means of all radiographic measurements improved from the injury film to the first postoperative follow-up. The measurements remained similar from the postoperative film to the first follow-up ( 4 weeks after surgery) with the exception of radial inclination and radial height, which showed the most significant difference from postoperative to the first follow-up after 4 weeks (52-42\% normal range for radial inclination and $14-23 \%$ normal range for radial height).

In contrast to this, the percentage of fractures with measurements in the normal ranges decreased in several fracture types (-Tables 3-7), which indicates a loss of reduction postoperatively in some fracture types.

If the change in mean was less than the documented standard deviation, we surmised these differences to be due to differing observer measurements or rotation of the radiograph.

However, when the change for each parameter from the initial to the final follow-up was greater than the standard deviation in at least three measurements, we reanalyzed the films to evaluate for loss of reduction. ${ }^{34}$

A total of seven fractures fell into this category. Of these, six had minimal or no loss of reduction, this could be attributed to changes in projection of the radiograph. One C2-fracture showed loss of reduction in the intermediate column and resulted in an ulnocarpal impaction syndrome.

We determined the loss of reduction by comparing ulnar variance from the first postoperative radiograph to the final radiograph. If the change to an ulna plus variant was more than the standard deviation, we deemed it as loss of reduction. ${ }^{34}$

At the final follow-up, following observations can be made: ulnar variance was the most likely parameter to retain reduction in comparison to the postoperative film.

Radial height was least likely to be restored to normal ranges of all the radiographic parameters following surgery (-Tables 3-7).

Radial inclination showed to be the least likely to maintain reduction within normal ranges from initial follow-up postoperatively to the final follow-up across all fracture types (-Tables 3-7). - Figure 5 shows the distribution of our measurements with the normal radiographic ranges and

Table 4 Values for the intra-operative X-ray film

\begin{tabular}{|c|c|c|c|c|c|}
\hline \multicolumn{6}{|c|}{ Measurements for postoperative film } \\
\hline & $n$ & Radial inclination & Radial height & Ulnar variance & Volar tilt \\
\hline Overall (\% [n]) & 166 & $52.41 \%(87)$ & $13.86 \%(23)$ & $61.45 \%(102)$ & $62.05 \%(103)$ \\
\hline \multicolumn{2}{|l|}{ Mean (SD) } & $24.02^{\circ}\left(3.29^{\circ}\right)$ & $11.22 \mathrm{~mm}(1.74 \mathrm{~mm})$ & $0.22 \mathrm{~mm}(1.77 \mathrm{~mm})$ & $11.98^{\circ}\left(6.19^{\circ}\right)$ \\
\hline \multicolumn{2}{|c|}{ Minimum to maximum } & $14.8^{\circ}$ to $31.8^{\circ}$ & 6.9 to $15.8 \mathrm{~mm}$ & -4 to $6.4 \mathrm{~mm}$ & $-11^{\circ}$ to $27^{\circ}$ \\
\hline \multicolumn{6}{|l|}{ AO class $(\%[n])$} \\
\hline A1 & 0 & $0 \%(0)$ & $0 \%(0)$ & $0 \%(0)$ & $0 \%(0)$ \\
\hline $\mathrm{A} 2$ & 32 & $56.25 \%(18)$ & $3.13 \%(1)$ & $46.86 \%(15)$ & $65.63 \%(21)$ \\
\hline $\mathrm{A} 3$ & 47 & $57.45 \%(27)$ & $10.64 \%(5)$ & $70.21 \%(33)$ & $63.83 \%(30)$ \\
\hline B1 & 6 & $33.33 \%(2)$ & $50 \%(3)$ & $50 \%(3)$ & $50 \%(3)$ \\
\hline B2 & 3 & $33.33 \%(1)$ & $0 \%(0)$ & $66.67 \%(2)$ & $100 \%(3)$ \\
\hline B3 & 0 & $0 \%(0)$ & $0 \%(0)$ & $0 \%(0)$ & $0 \%(0)$ \\
\hline $\mathrm{C} 1$ & 30 & $50 \%(15)$ & $10 \%(3)$ & $70 \%(21)$ & $46.67 \%(14)$ \\
\hline $\mathrm{C2}$ & 25 & $44 \%(11)$ & $20 \%(5)$ & $68 \%(17)$ & $68 \%(17)$ \\
\hline C3 & 23 & $56.52 \%(13)$ & $26.01 \%(6)$ & $47.83 \%(11)$ & $65.22 \%(15)$ \\
\hline \multicolumn{6}{|c|}{ Fernandez class (\% [n]) } \\
\hline 1 & 74 & $52.7 \%(39)$ & $8.11 \%(6)$ & $62.16 \%(46)$ & $62.16 \%(46)$ \\
\hline 2 & 10 & $40 \%(4)$ & $60 \%(6)$ & $70 \%(7)$ & $100 \%(10)$ \\
\hline 3 & 80 & $55 \%(44)$ & $12.5 \%(10)$ & $60 \%(48)$ & $57.5 \%(46)$ \\
\hline 4 & 0 & $0 \%(0)$ & $0 \%(0)$ & $0 \%(0)$ & $0 \%(0)$ \\
\hline 5 & 2 & $0 \%(0)$ & $50 \%(1)$ & $50 \%(1)$ & $50 \%(1)$ \\
\hline
\end{tabular}

Abbreviation: SD, standard deviation. 
Table 5 Values for the 4 weeks post-op X-ray film

\begin{tabular}{|c|c|c|c|c|c|}
\hline \multicolumn{6}{|c|}{ Measurements for first follow-up } \\
\hline & $n$ & Radial inclination & Radial height & Ulnar variance & Volar tilt \\
\hline Overall $(\%[n])$ & 166 & $42.17 \%(70)$ & $22.89 \%(38)$ & $65.66 \%(109)$ & $57.83 \%(96)$ \\
\hline \multicolumn{2}{|l|}{ Mean (SD) } & $25.23^{\circ}\left(3.31^{\circ}\right)$ & $11.78 \mathrm{~mm}(1.69 \mathrm{~mm})$ & $0.74 \mathrm{~mm}(1.71 \mathrm{~mm})$ & $12.91^{\circ}\left(6.58^{\circ}\right)$ \\
\hline \multicolumn{2}{|c|}{ Minimum to maximum } & $17.9^{\circ}$ to $32.4^{\circ}$ & 8 to $15.8 \mathrm{~mm}$ & -3.5 to $8.2 \mathrm{~mm}$ & $-16^{\circ}$ to $27.8^{\circ}$ \\
\hline \multicolumn{6}{|l|}{ AO class $(\%[n])$} \\
\hline A1 & 0 & $0 \%(0)$ & $0 \%(0)$ & $0 \%(0)$ & $0 \%(0)$ \\
\hline$A 2$ & 32 & $37.5 \%(12)$ & $18.75 \%(6)$ & $65.63 \%(21)$ & $53.13 \%(17)$ \\
\hline A3 & 47 & $34.04 \%(16)$ & $17.02 \%(8)$ & $76.6 \%(36)$ & $57.45 \%(27)$ \\
\hline B1 & 6 & $50 \%(3)$ & $33.33 \%(2)$ & $33.33 \%(2)$ & $50 \%(3)$ \\
\hline B2 & 3 & $0 \%(0)$ & $0 \%(0)$ & $33.33 \%(1)$ & $66.67 \%(2)$ \\
\hline B3 & 0 & $0 \%(0)$ & $0 \%(0)$ & $0 \%(0)$ & $0 \%(0)$ \\
\hline $\mathrm{C} 1$ & 30 & $43.33 \%(13)$ & $26.67 \%(8)$ & $70 \%(21)$ & $60 \%(18)$ \\
\hline $\mathrm{C} 2$ & 25 & $60 \%(15)$ & $24 \%(6)$ & $64 \%(16)$ & $56 \%(14)$ \\
\hline C3 & 23 & $47.83 \%(11)$ & $34.78 \%(8)$ & $52.17 \%(12)$ & $65.22 \%(15)$ \\
\hline \multicolumn{6}{|c|}{ Fernandez class (\% [n]) } \\
\hline 1 & 74 & $36.49 \%(27)$ & $17.57 \%(13)$ & $70.27 \%(52)$ & $52.7 \%(39)$ \\
\hline 2 & 10 & $40 \%(4)$ & $50 \%(5)$ & $50 \%(5)$ & $70 \%(7)$ \\
\hline 3 & 80 & $47.5 \%(38)$ & 23.75\% (19) & $62.5 \%(50)$ & $61.25 \%(49)$ \\
\hline 4 & 0 & $0 \%(0)$ & $0 \%(0)$ & $0 \%(0)$ & $0 \%(0)$ \\
\hline 5 & 2 & $50 \%(1)$ & $50 \%(1)$ & $100 \%(2)$ & $50 \%(1)$ \\
\hline
\end{tabular}

Abbreviation: SD, standard deviation.

Table 6 Values for the 8 weeks post-operative X-ray film

\begin{tabular}{|c|c|c|c|c|c|}
\hline \multicolumn{6}{|c|}{ Measurements for second follow-up } \\
\hline & $N$ & Radial inclination & Radial height & Ulnar variance & Volar tilt \\
\hline Overall $(\%[n])$ & 166 & $43.37 \%(72)$ & $18.67 \%(31)$ & $62.05 \%(103)$ & $57.23 \%(95)$ \\
\hline \multicolumn{2}{|l|}{ Mean (SD) } & $25.6^{\circ}\left(3.36^{\circ}\right)$ & $11.85 \mathrm{~mm}(1.75 \mathrm{~mm})$ & $0.89 \mathrm{~mm}(1.78 \mathrm{~mm})$ & $13.8^{\circ}\left(6.48^{\circ}\right)$ \\
\hline \multicolumn{2}{|l|}{$\begin{array}{l}\text { Minimum to } \\
\text { maximum }\end{array}$} & $17.7^{\circ}$ to $36.4^{\circ}$ & 7.2 to $17.2 \mathrm{~mm}$ & $-3.7 \mathrm{~mm}$ to $7.6 \mathrm{~mm}$ & $-23.5^{\circ}$ to $28.4^{\circ}$ \\
\hline \multicolumn{6}{|l|}{ AO class $(\%[n])$} \\
\hline A1 & 0 & $0 \%(0)$ & $0 \%(0)$ & $0 \%(0)$ & $0 \%(0)$ \\
\hline $\mathrm{A} 2$ & 32 & $37.5 \%(12)$ & $18.75 \%(6)$ & $50 \%(16)$ & $59.38 \%(19)$ \\
\hline A3 & 47 & $44.68 \%(21)$ & $21.28 \%(10)$ & $70.21 \%(33)$ & $57.45 \%(27)$ \\
\hline B1 & 6 & $16.67 \%(1)$ & $16.67 \%(1)$ & $50 \%(3)$ & $50 \%(3)$ \\
\hline B2 & 3 & $33.33 \%(1)$ & $0 \%(0)$ & $33.33 \%(1)$ & $33.33 \%(1)$ \\
\hline B3 & 0 & $0 \%(0)$ & $0 \%(0)$ & $0 \%(0)$ & $0 \%(0)$ \\
\hline $\mathrm{C} 1$ & 30 & $46.67 \%(14)$ & $13.33 \%(4)$ & $66.67 \%(20)$ & $63.33 \%(19)$ \\
\hline $\mathrm{C} 2$ & 25 & $52 \%(13)$ & $16 \%(4)$ & $76 \%(19)$ & $52 \%(13)$ \\
\hline $\mathrm{C} 3$ & 23 & $43.48 \%(10)$ & $26.09 \%(6)$ & $47.83 \%(11)$ & $56.52 \%(13)$ \\
\hline \multicolumn{6}{|c|}{ Fernandez class (\% [n]) } \\
\hline 1 & 74 & $44.59 \%(33)$ & $18.92 \%(14)$ & $60.81 \%(45)$ & $55.41 \%(41)$ \\
\hline 2 & 10 & $30 \%(3)$ & $40 \%(4)$ & $30 \%(3)$ & $50 \%(5)$ \\
\hline 3 & 80 & $43.75 \%(35)$ & $15 \%(12)$ & $67.5 \%(54)$ & $58.75 \%(47)$ \\
\hline
\end{tabular}


Table 6 (Continued)

\begin{tabular}{|l|l|l|l|l|l|}
\hline Measurements for second follow-up \\
\hline & $N$ & Radial inclination & Radial height & Ulnar variance & Volar tilt \\
\hline 4 & 0 & $0 \%$ & $0 \%(0)$ & $0 \%(0)$ & $0 \%(0)$ \\
\hline 5 & 2 & $50 \%(1)$ & $50 \%(1)$ & $50 \%(1)$ & $100 \%(2)$ \\
\hline
\end{tabular}

Abbreviation: SD, standard deviation.

Table 7 Values for the 1 year postop follow-up X-ray film after removal of implants

\begin{tabular}{|l|l|l|l|l|l|}
\hline \multicolumn{2}{|l|}{ Measurements for third follow-up (after implant removal) } \\
\hline & $N$ & Radial inclination & Radial height & Ulnar variance & Volar tilt \\
\hline Overall (\% [n]) & 166 & $37.95 \%(63)$ & $24.7 \%(41)$ & $60.24 \%(100)$ & $50 \%(83)$ \\
\hline Mean (SD) & $25.54^{\circ}\left(3.09^{\circ}\right)$ & $12.17 \mathrm{~mm}(2.14 \mathrm{~mm})$ & $1.23 \mathrm{~mm}(1.75 \mathrm{~mm})$ & $14.06^{\circ}\left(6.65^{\circ}\right)$ \\
\hline \multicolumn{7}{|l|}{ Minimum to maximum } & $14.3^{\circ}$ to $32.2^{\circ}$ & 5.6 to $29.8 \mathrm{~mm}$ & -3.2 to $6.4 \mathrm{~mm}$ & $-19.7^{\circ}$ to $27.3^{\circ}$ \\
\hline AO class (\% [n]) & \multicolumn{5}{|l|}{} \\
\hline A1 & 0 & $0 \%(0)$ & $0 \%(0)$ & $0 \%(0)$ & $0 \%(0)$ \\
\hline A2 & 32 & $25 \%(8)$ & $25 \%(8)$ & $75 \%(24)$ & $56.25 \%(18)$ \\
\hline A3 & 47 & $36.17 \%(17)$ & $14.89 \%(7)$ & $65.96 \%(31)$ & $48.94 \%(23)$ \\
\hline B1 & 6 & $33.33 \%(2)$ & $33.33 \%(2)$ & $50 \%(3)$ & $66.67 \%(4)$ \\
\hline B2 & 3 & $0 \%(0)$ & $0 \%(0)$ & $33.33 \%(1)$ & $0 \%(0)$ \\
\hline B3 & 0 & $0 \%(0)$ & $26.67 \%(8)$ & $0 \%(0)$ & $0 \%(0)$ \\
\hline C1 & 30 & $43.33 \%(13)$ & $24 \%(6)$ & $64.33 \%(13)$ & $53.33 \%(16)$ \\
\hline C2 & 25 & $48 \%(12)$ & $43.48 \%(10)$ & $52.17 \%(12)$ & $52 \%(13)$ \\
\hline C3 & 23 & $47.83 \%(11)$ & & & $39.13 \%(9)$ \\
\hline Fernandez class (\% $[n])$ & 74 & $36.49 \%(27)$ & $17.57 \%(13)$ & $71.62 \%(53)$ & $50 \%(37)$ \\
\hline 1 & 10 & $30 \%(3)$ & $40 \%(4)$ & $40 \%(4)$ & $50 \%(5)$ \\
\hline 2 & 80 & $40 \%(32)$ & $28.75 \%(23)$ & $52.5 \%(42)$ & $48.75 \%(39)$ \\
\hline 3 & 0 & $0 \%(0)$ & $0 \%(0)$ & $0 \%(0)$ & $0 \%(0)$ \\
\hline 4 & 2 & $50 \%(1)$ & $50 \%(1)$ & $50 \%(1)$ & $100 \%(2)$ \\
\hline 5 & Gap & & & \\
\hline Step-off & $96.99 \%(161)$ & & & \\
\hline $99.4 \%(165)$ & & & \\
\hline
\end{tabular}

Abbreviation: SD, standard deviation.

functional ranges ${ }^{28,29,31,32}$ (dotted line) for reference. While most fractures fell into the radiographic norms, some measurements such as radial height and radial inclination show a collective shift outside the norm when comparing the postoperative and second follow-up after 8 weeks.

\section{Complications}

We recorded a total of 15 clinical complications: none of them were implant-related (categorized by ClavienDindo). ${ }^{35}$

Grade I: Five patients developed a complex regional pain syndrome (CRPS; one type II, four type I) which required extended conservative treatment.

Grade III: One patient developed a symptomatic ulnar impaction with posttraumatic shortening of the radius which required corrective osteotomy. Two cases developed a symptomatic CTS (one of which had a simultaneous CRPS) which required surgical decompression. In one patient a ruptured extensor tendon of the index finger was found and sutured during removal of the plate, though it is unclear if the rupture occurred intraoperatively during the approach or postoperatively through irritation by the implant. The patient had not complained about issues in this regard. One patient had iatrogenic lesion of the extensor pollicis longus during osteosynthesis of the fracture, which was sutured and showed no problems postoperatively. Three patients with reduced range of motion showed adhesions of the extensor tendons and required operative tenolysis. Two patients developed posttraumatic and symptomatic radiocarpal arthritis but refused further interventions. 


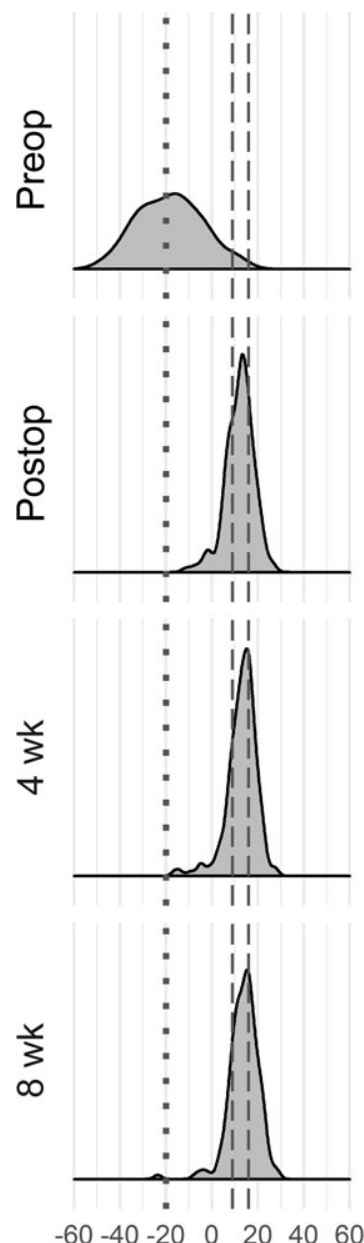

Palmar tilt degree

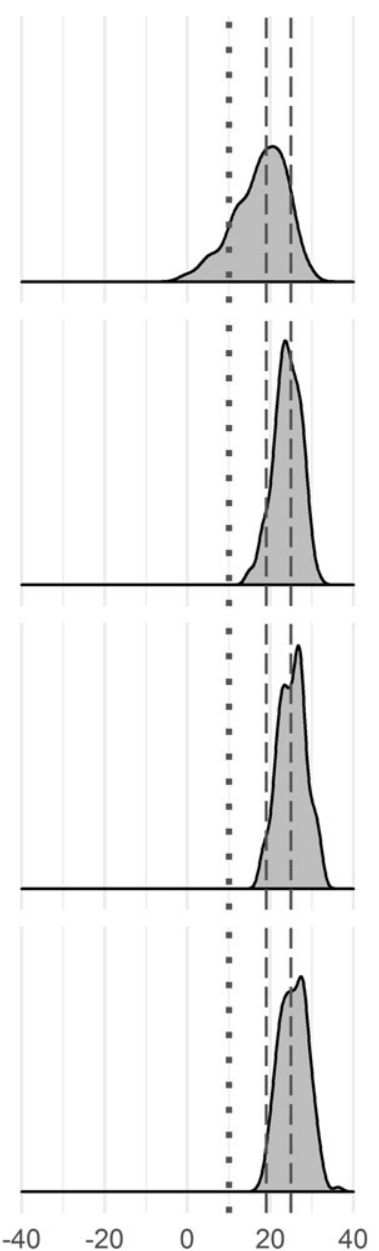

Radial inclination degree
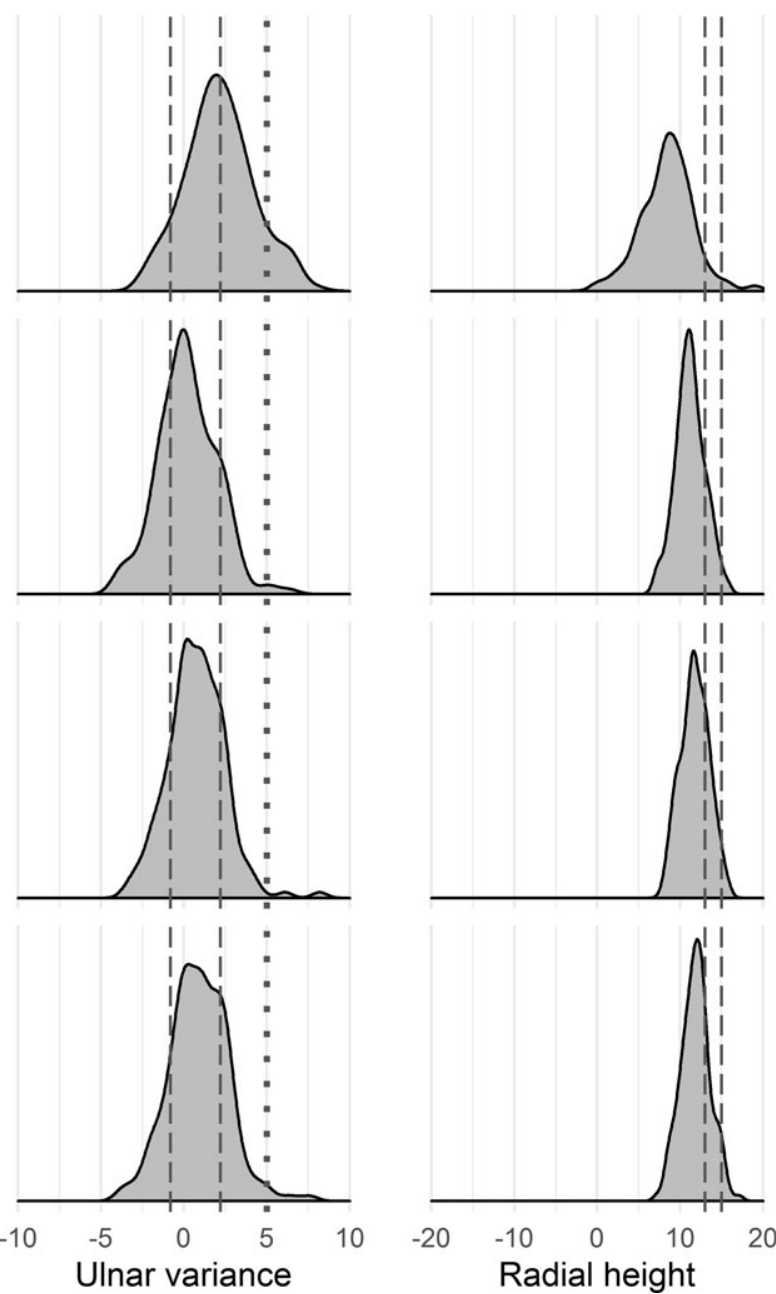

Fig. 5 Distribution graph of palmar tilt, radial inclination, ulnar variance, and radial height over time 4 points: injury, postoperative, first followup (4 weeks), and second follow-up ( 8 weeks). Radiographic normal range (as seen in - Table 2 ) and functional normal range ( $<20^{\circ}$ dorsal angulation, $>10^{\circ}$ radial inclination, $<5 \mathrm{~mm}$ ulnar variance).

\section{Discussion}

Our results show that dorsal plating of distal radius fractures, when performed correctly and by experienced surgeons, provides outcomes on par with the more commonly performed volar plate osteosynthesis when considering radiographic parameters and complication rate.

It has been proven that anatomic reduction of distal radius fractures is essential in terms of functional outcome and physiological biomechanics. ${ }^{32,34,36}$ Studies have also shown that radial inclination $<20^{\circ}, 37,38$ loss of radial height $>6 \mathrm{~mm}^{39,40}$ volar tilt $<5^{\circ},{ }^{29}$ and ulnar variance $>5 \mathrm{~mm}^{29,41}$ were associated with poor outcome. A satisfactory functional outcome could nonetheless be achieved despite measurements outside these limits in some cases. ${ }^{42-44}$

The results of our radiographic measurements are comparable to those by Mignemi et $\mathrm{al}^{34}$ for volar locking plating. Radiographic measurements in the normal range in the final postoperative follow-up were achieved in $38 \%$ for radial inclination (43\%; Mignemi et al.), 25\% for radial height (12\%), $60 \%$ for ulnar variance (52\%), and $50 \%$ for volar tilt
(48\%). For radiocarpal step-off, 99\% achieved measurements in a normal range (Mignemi et al, 92\%). Radial height was least likely to be restored from first to final follow-up in our study.

Only two tendon ruptures were documented in our patient pool: one was of iatrogenic nature during initial surgery and the second (rupture of extensor digitorum II) could not be fully attributed to the plate used.

Yu et al compared complication rate between low-profile dorsal plates and volar, and there was no significant difference in tendon irritation or rupture between the two techniques. ${ }^{45}$ Several studies attributed the high amount of tendon rupture/irritation and subsequent need for implant removal to one specific implant (Synthes Pi-plate). ${ }^{14,46,47}$ Results with low-profile implants have shown better results. ${ }^{17,42,48-51}$

Strong points of our study were the large cohort number (i.e., compared with Kamath et $\mathrm{al}^{48}$ ) and the large number of AO/OTA class A fractures, for which a volar approach was more commonly used.

Limitations of our study are the single-center and retrospective nature as well as the lack of inclusion of clinical 
parameters. When measuring the radiographs, patient details were removed but the observers were not blinded to the results of the radiographic evaluation. We also decided not to include clinical observations such as range of motion, as they were not completely documented in the clinical files and we wanted to focus only on radiographic results. By excluding very complex fractures needing additional fixation (K-wires, additional plating, operative treatment of an ulnar fracture), we cannot conclude anything on these types of complex fracture treatment.

The modern concept of treatment of simple and complex distal radius fractures focuses on the dislocation direction and consecutive dislocation of the carpus as an additional force which needs to be addressed to avoid loss of reduction and failure of the implant due to exceeding forces. ${ }^{11,52,53}$

Based on modern concept for the treatment of distal radius fractures in combination with our results, we recommend colleagues treating distal radius fractures to evaluate which approach to take on a case-by-case basis, especially when treating unstable, dorsally displaced fractures with consecutive dorsal dislocation of the carpus and dorso-ulnar corner fragments.

\section{Ethical Review Approval}

The study has been approved by the local ethical committee (EKNZ 2016-00303).

\section{Conflict of Interest}

P.H. and M.H. are consultants at Medartis AG, Basel, Switzerland and do not have any financial benefit because of this publication.

\section{Acknowledgment}

The authors thank Regula Steiger, MD, for her pioneering work in the treatment of distal radius fractures and reviewing this manuscript, and Lukas Zwicky, Manja Deforth, Christine Schweizer, and Roman Susdorf for their statistical support.

\section{References}

1 Leung F, Zhu L, Ho H, Lu WW, Chow SP. Palmar plate fixation of AO type $\mathrm{C} 2$ fracture of distal radius using a locking compression plate-a biomechanical study in a cadaveric model. J Hand Surg [Br] 2003;28(03):263-266

2 Rein S, Schikore H, Schneiders W, Amlang M, Zwipp H. Results of dorsal or volar plate fixation of AO type $\mathrm{C} 3$ distal radius fractures: a retrospective study. J Hand Surg Am 2007;32(07):954-961

$3 \mathrm{Ng} \mathrm{CY}$, McQueen MM. What are the radiological predictors of functional outcome following fractures of the distal radius? J Bone Joint Surg Br 2011;93(02):145-150

4 Martineau PA, Berry GK, Harvey EJ. Plating for distal radius fractures. Orthop Clin North Am 2007;38(02):193-201, vi

5 Ruch DS, Papadonikolakis A. Volar versus dorsal plating in the management of intra-articular distal radius fractures. J Hand Surg Am 2006;31(01):9-16

6 Catalano LW III, Barron OA, Glickel SZ. Assessment of articular displacement of distal radius fractures. Clin Orthop Relat Res 2004;(423):79-84

7 Osada D, Viegas SF, Shah MA, Morris RP, Patterson RM. Comparison of different distal radius dorsal and volar fracture fixation plates: a biomechanical study. J Hand Surg Am 2003;28(01): 94-104

8 Kamano M, Honda Y, Kazuki K, Yasuda M. Palmar plating for dorsally displaced fractures of the distal radius. Clin Orthop Relat Res 2002;(397):403-408

9 Orbay JL, Fernandez DL. Volar fixation for dorsally displaced fractures of the distal radius: a preliminary report. J Hand Surg Am 2002;27(02):205-215

10 Ruch DS, Weiland AJ, Wolfe SW, Geissler WB, Cohen MS, Jupiter JB. Current concepts in the treatment of distal radial fractures. Instr Course Lect 2004;53:389-401

11 Hintringer W, Rosenauer R, Pezzei C, et al. Biomechanical considerations on a CT-based treatment-oriented classification in radius fractures. Arch Orthop Trauma Surg 2020;140(05):595-609

12 Tavakolian JD, Jupiter JB. Dorsal plating for distal radius fractures. Hand Clin 2005;21(03):341-346

13 Wei J, Yang TB, Luo W, Qin JB, Kong FJ. Complications following dorsal versus volar plate fixation of distal radius fracture: a metaanalysis. J Int Med Res 2013;41(02):265-275

14 Kambouroglou GK, Axelrod TS. Complications of the AO/ASIF titanium distal radius plate system (pi plate) in internal fixation of the distal radius: a brief report. J Hand Surg Am 1998;23(04): 737-741

15 Rozental TD, Beredjiklian PK, Bozentka DJ. Functional outcome and complications following two types of dorsal plating for unstable fractures of the distal part of the radius. J Bone Joint Surg Am 2003;85(10):1956-1960

16 Schnur DP, Chang BArbeitsgemeinschaft für Osteosynthesefragen/ Association for the Study of Internal Fixation. Extensor tendon rupture after internal fixation of a distal radius fracture using a dorsally placed AO/ASIF titanium pi plate. Ann Plast Surg 2000;44 (05):564-566

17 Devaux N, Henning J, Haefeli M, Honigmann P. The retinaculum flap for dorsal fixation of distal radius fractures. J Hand Surg Am 2018;43(04):391.e1-391.e7

18 Kumar S, Khan AN, Sonanis SV. Radiographic and functional evaluation of low profile dorsal versus volar plating for distal radius fractures. J Orthop 2016;13(04):376-382

19 Pallaver A, Honigmann P. The role of cone-beam computed tomography (CBCT) scan for detection and follow-up of traumatic wrist pathologies. J Hand Surg Am 2019;44(12):1081-1087

20 Honigmann P, Frueh FS. Letter about a published paper. J Hand Surg Eur Vol 2018;43(04):451

21 Fernández DL. Fractures of the distal radius: operative treatment. Instr Course Lect 1993;42:73-88

22 Meinberg EG, Agel J, Roberts CS, Karam MD, Kellam JF. Fracture and dislocation classification compendium-2018. J Orthop Trauma 2018;32(Suppl 1):S1-S170

23 Herzberg G. Acute distal radius fracture: PAF analysis. J Wrist Surg 2013;2(01):95-96

24 Jupiter JB. Fractures of the distal end of the radius. J Bone Joint Surg Am 1991;73(03):461-469

25 Mekhail AO, Ebraheim NA, McCreath WA, Jackson WT, Yeasting RA. Anatomic and X-ray film studies of the distal articular surface of the radius. J Hand Surg Am 1996;21(04):567-573

26 Mann FA, Raissdana SS, Wilson AJ, Gilula LA. The influence of age and gender on radial height. J Hand Surg Am 1993;18(04): 711-713

27 Jung JM, Baek GH, Kim JH, Lee YH, Chung MS. Changes in ulnar variance in relation to forearm rotation and grip. J Bone Joint Surg Br 2001;83(07):1029-1033

28 Porter M, Stockley I. Fractures of the distal radius. Intermediate and end results in relation to radiologic parameters. Clin Orthop Relat Res 1987;(220):241-252

29 Mann FA, Wilson AJ, Gilula LA. Radiographic evaluation of the wrist: what does the hand surgeon want to know? Radiology 1992;184(01):15-24 
30 Medoff RJ. Essential radiographic evaluation for distal radius fractures. Hand Clin 2005;21(03):279-288

31 Altissimi M, Antenucci R, Fiacca C, Mancini GB. Long-term results of conservative treatment of fractures of the distal radius. Clin Orthop Relat Res 1986;(206):202-210

32 Knirk JL, Jupiter JB. Intra-articular fractures of the distal end of the radius in young adults. J Bone Joint Surg Am 1986;68(05):647-659

33 Lalone EA, Grewal R, King GJ, MacDermid JC. A structured review addressing the use of radiographic measures of alignment and the definition of acceptability in patients with distal radius fractures. Hand (N Y) 2015;10(04):621-638

34 Mignemi ME, Byram IR, Wolfe CC, et al. Radiographic outcomes of volar locked plating for distal radius fractures. J Hand Surg Am 2013;38(01):40-48

35 Clavien PA, Barkun J, de Oliveira ML, et al. The Clavien-Dindo classification of surgical complications: five-year experience. Ann Surg 2009;250(02):187-196

36 Synn AJ, Makhni EC, Makhni MC, Rozental TD, Day CS. Distal radius fractures in older patients: is anatomic reduction necessary? Clin Orthop Relat Res 2009;467(06):1612-1620

37 Chen NC, Jupiter JB. Management of distal radial fractures. J Bone Joint Surg Am 2007;89(09):2051-2062

38 Rubinovich RM, Rennie WR. Colles' fracture: end results in relation to radiologic parameters. Can J Surg 1983;26(04):361-363

39 Trumble TE, Schmitt SR, Vedder NB. Factors affecting functional outcome of displaced intra-articular distal radius fractures. J Hand Surg Am 1994;19(02):325-340

40 Batra S, Gupta A. The effect of fracture-related factors on the functional outcome at 1 year in distal radius fractures. Injury 2002;33(06):499-502

41 Lee SJ, Park JW, Kang BJ, Lee JI. Clinical and radiologic factors affecting functional outcomes after volar locking plate fixation of dorsal angulated distal radius fractures. J Orthop Sci 2016;21(05): 619-624

42 Chou YC, Chen AC, Chen CY, Hsu YH, Wu CC. Dorsal and volar 2.4$\mathrm{mm}$ titanium locking plate fixation for AO type C3 dorsally comminuted distal radius fractures. J Hand Surg Am 2011;36 (06):974-981
43 Catalano LW III, Cole RJ, Gelberman RH, Evanoff BA, Gilula LA, Borrelli J Jr. Displaced intra-articular fractures of the distal aspect of the radius. Long-term results in young adults after open reduction and internal fixation. J Bone Joint Surg Am 1997;79 (09):1290-1302

44 Plant CE, Parsons NR, Costa ML. Do radiological and functional outcomes correlate for fractures of the distal radius? Bone Joint J 2017;99-B(03):376-382

45 Yu YR, Makhni MC, Tabrizi S, Rozental TD, Mundanthanam G, Day CS. Complications of low-profile dorsal versus volar locking plates in the distal radius: a comparative study. J Hand Surg Am 2011;36 (07):1135-1141

46 Ring D, Jupiter JB, Brennwald J, Büchler U, Hastings H II. Prospective multicenter trial of a plate for dorsal fixation of distal radius fractures. J Hand Surg Am 1997;22(05):777-784

47 Chiang PP, Roach S, Baratz ME. Failure of a retinacular flap to prevent dorsal wrist pain after titanium Pi plate fixation of distal radius fractures. J Hand Surg Am 2002;27(04):724-728

48 Kamath AF, Zurakowski D, Day CS. Low-profile dorsal plating for dorsally angulated distal radius fractures: an outcomes study. J Hand Surg Am 2006;31(07):1061-1067

49 Letsch R, Infanger M, Schmidt J, Kock HJ. Surgical treatment of fractures of the distal radius with plates: a comparison of palmar and dorsal plate position. Arch Orthop Trauma Surg 2003;123 (07):333-339

50 Matzon JL, Kenniston J, Beredjiklian PK. Hardware-related complications after dorsal plating for displaced distal radius fractures. Orthopedics 2014;37(11):e978-e982

51 Rikli DA, Regazzoni P. Fractures of the distal end of the radius treated by internal fixation and early function. A preliminary report of 20 cases. J Bone Joint Surg Br 1996;78(04):588-592

52 Shaerf DA, Halsey TJ. Mechanical failure of the distal radius volar rim plate: a case report. J Hand Surg Eur Vol 2019;44(10): 1094-1096

53 Honigmann P, Sutter D. Re: Shaerf DA and Halsey TJ. Mechanical failure of the distal radius volar rim plate: a case report. J Hand Surg Eur. 2019, 44: 1094-6. J Hand Surg Eur Vol 2020;45(05): $531-532$ 